\title{
APLIKASI BRIEF PAIN INVENTORY(BPI) INDONESIAN VERSION UNTUK MENGKAJI NYERI KRONIS PADA PASIEN KANKER
}

\author{
Arie Jefry Ka'arayeno \\ Universitas Tribhuwana Tunggadewi Malang \\ E-mail : jefryarie@ymail.com
}

\begin{abstract}
For cancer patients the pain will have an impact on quality of life, is complex and greatly affects daily activities. Pain management is currently felt to be not enough to relieve complaints. One major obstacle to improvement is narrow assessment, as well as an assessment focus that does not consider the multidimensional nature of pain. The Center for Symptom Evaluation in Cancer Care has developed a specific pain assessment for cancer patients, the Brief Pain Inventory (BPI). The purpose of this study is to prove and see the suitability of the Indonesian version of BPI as a study of pain in cancer patients at RSCM Jakarta. Research respondents were 20 cancer patients with pain and observed using the Brief Pain Inventory (BPI) instrument. Based on the results of the Cronbach's alpha test from BPI it is known as 0.723. These results show that BPI is appropriate and consistent in assessing cancer pain, especially chronic pain, and has a good correlation based on the Spearman correlation with ECOG values $(r=-0.75, p=$ 0.0001). The sensitivity test is known to be $95.7 \%$, specificity $100 \%$, PPV 100\%, NPV 65.67\%, LR (-) 0.05 , with diagnostic accuracy of $95.73 \%$. BPI is a more multidimensional assessment as a description of biological, psychological, social and cultural conditions of cancer patients who experience pain, so that BPI is suitable for use in the scope of oncology nursing in assessing chronic pain in cancer patients.
\end{abstract}

Keywords : Briefpain inventory; cancer pain; assessment.

\begin{abstract}
ABSTRAK
Bagi pasien kanker rasa sakit akan berdampak pada kualitas hidup, bersifat kompleks dan sangat mempengaruhi aktivitas sehari-hari. Pengelolaan nyeri saat ini dirasakan tidak cukup mampu melegakan keluhan.Salah satu hambatan utama untuk perbaikanadalah penilaian yang bersifat sempit, serta fokus penilaian yang tidakmempertimbangkan sifat multidimensi nyeri.Centre for Symptom Evaluation in Cancer Care telah mengembangkan sebuah pengkajian nyeri yang spesifik bagi pasien kanker, yaitu Brief Pain Inventory (BPI). Tujuan penelitian ini adalah untuk membuktikan dan melihat kesesuaian BPI versi bahasa Indonesia sebagai pengkajian nyeri pada pasien kanker di RSCM Jakarta.Responden penelitian adalah 20 orangpasien kanker dengan nyeridan diobservasi menggunakan instrument Brief Pain Inventory (BPI).Berdasarkan hasil uji cronbach's alphadari BPI diketahui sebesar 0.723. Hasil
\end{abstract}

Cara mengutip: Ka'arayeno, A., Jefry. (2020). Aplikasi Brief Pain Inventory (BPI) Indonesian Version untuk Mengkaji Nyeri Kronis pada Pasien Kanker. Care:Jurnal Ilmiah Ilmu Kesehatan, 8(2), 294-305 
tersebut memperlihatkan BPI sesuai dan konsisten dalam mengkaji nyeri kanker khususnya nyeri kronis, serta memiliki korelasi yang baik berdasarkan korelasi spearmandengan nilai ECOG $(r=-0,75, p=0,0001)$ yaitu uji sensitifitas diketahui sebesar $95.7 \%$, spesifisitas $100 \%$, PPV 100\%, NPV 65.67\%, LR (-) 0.05, dengan akurasi diagnostik 95.73\%. BPImerupakan penilaian yang lebih multidimensial sebagai gambaran kondisi biologis, psikologis, social dan kultulral pasien kanker yang mengalami nyeri, sehingga BPI sesuai digunakan pada ruang lingkup keperawatan onkologi dalam mengkaji nyeri kronis pada pasien kanker.

Kata Kunci : Brief pain inventory; nyeri kanker; pengkajian.

\section{PENDAHULUAN}

Dalam populasi onkologis, nyeri adalah salah satu gejala yang paling sering mengalami kesalahan penilaian yaitu sebesar 66\% dari kasus pada pasien kanker di dunia (Caraceni A \& Shkodra M, 2019). Karena nyeri kanker bukan entitas yang homogen, sehingga penilaian yang sesuai sangat penting untuk mendapatkan manajemen yang memuaskan.Nyeri kanker adalah istilah umum yang luas meliputi berbagai kondisi nyeri yang berbeda, ditandai oleh etiologi, karakteristik, dan mekanisme patologis yang berbeda(Matthie $\mathrm{N} \&$ McMillan S, 2014).Pentingnya penilaian nyeri yang memadai dari kompleksitas nyeri kanker telah ditekankan untuk waktu yang sangat lama. Mempertimbangkan pentingnya klasifikasi nyeri dalam menyediakan penilaian individu dan strategi perawatan khusus, selama bertahun-tahun beberapa kelompok telah berusaha untuk menemukan pendekatan komprehensif untuk mengklasifikasikan nyeri kanker (Erol O et al, 2018).

Nyeri merupakan salah satu dari banyak gejala yang paling umum pada pasien kanker, khususnya nyeri kronis. Nyeri didefinisikan oleh The International Association For The Study of Pain sebagai suatu bentuk indra atau interperetasi yang tidak menyenangkan, meyakitkan, mengganggu dan pengalaman emosional yang timbul dari aktual atau potensial kerusakan jaringan atau dijelaskan dalam hal itu merupakan hasil dari kerusakan sebuah jaringan. Ferrell Dean (1995) menggambarkan rasa nyeri sebagai satu gejala yang paling umum dan tak tertahankan yang dirasakan pasien kanker. Sebanyak 80\% dari Pasien dengan kanker stadium lanjut mengalami rasa nyeri selama perjalanan penyakit mereka (Hill et all, 2001).

Berdasarkan Data GLOBOCAN, International Agency for Research on Cancer (IARC), diketahui bahwa pada 
tahun 2012 saja terdapat 14.067 .894 kasus baru kanker dan 8.201.575 kematian akibat kanker di seluruh dunia. Sedangkan untuk regional berdsarkan Riset Kesehatan Dasar (Riskesdas) yang dilaksanakan oleh Badan Penelitian dan Pengembangan Kesehatan, Kementerian Kesehatan RI tahun 2013, didapatkan prevalensi penderita kanker pada penduduk semua umur di Indonesia sebesar 1,4\%. Prevalensi kanker tertinggi berada pada Provinsi DI Yogyakarta, yaitu sebesar 4,1\%. Prevalensi tertinggi berikutnya berada pada Provinsi Jawa Tengah dan Bali, yaitu sebesar 2,1\% dan $2 \%$.

Oligoanalgesia atau rasa nyeri, dipahami menjadi masalah yang signifikan namun kurang dipahami (NIH. National Institute of Health State of the Science Statement, 2002) Hambatan yang terjadi terhadap pengobatan meliputi takut efek samping, ketakutan toleransi dan kecanduan, fatalisme dalam hal pengobatan rasa sakit, dan dosis obat yang tidak adekuat(Dawson $R$, 2005). Sehingga penilaian nyeri yang tepat dipertimbangkan menjadi sebuah prasyarat untuk perawatan nyeri yang tepat. Namun demikian penelitian yang menunjukkan penilaian atau pengkajian rasa nyeri dirasakan masih belum cukup, dan tidak dikelola secara memuaskan (Caraceni A \& Shkodra M, 2019).

Umumnya layanan kesehatan kita masih sangat luas menggunakan instrument visual analog scale (VAS). VAS merupakan alat dengan garis $10 \mathrm{~cm}$, orientasi biasanya disajikan secara horizontal, tapi mungkin bisa disajikan secara vertikal, pada akhir poin dengan kata tidak nyeri sampai pada nyeri paling hebat yang tidak terbayangkan.Vas merupakan salah satu pengkajian nyeri pada pasien yang biasa digunakan.VAS secara umum lebih singkat, mudah dan sederhana, sehingga pengkajian VAS tidak memerlukan waktu yang lama.Namun VAS sendiri hanya dapat mengetahui data pasien berupa intensitas nyeri yang dirasakan pasien pada saat itu saja, selain itu VAS tidak megkaji kualitas nyeri bahkan respon pasien terhadap nyeri tersebut.

Holen et al (2006) menuliskan dalam penelitiannya bahwa terdapat sebuah survey di antara 897 dokter di The Eastern Cooperative Oncology Group, 76\% dilaporkan penilaian nyeri sebagai single yang paling penting dan menjadi salah satu hambatan untuk pengelolaan nyeri yang memadai. Dengan demikian, penilaian berkala terhadap nyeri kanker penting untuk identifikasi dini guna menunjang 
pengobatan kanker dan kualitas hidup pasien (Cluxton C, 2019). Sentil P Kumar (2011) menyebutkan dalam tulisannya, bahwa The World Health atau Organization Organisasi Kesehatan Dunia (WHO) melalui Centre for Symptom Evaluation in Cancer Care telah mengembangkan sebuah pengkajian nyeri yang spesifik pada pasien kanker, yaitu Brief Pain Inventory (BPI).

Kebutuhan akan penilaian nyeri klinis yang efisien dan alat ukur dalam perawatan paliatif untuk pasien dengan kanker menjadi salah satu fokus praktisi kesehatan saat ini (Rahi C E et al, 2017). Untuk menjawab kebutuhan tersebut Brief Pain Inventory (BPI) menjadi salah satu pilihan yang baik berdasarkan penelitian sebelumnya. Dibeberapa Negara bahkan benua, BPI adalah alat atau instrument yang valid dan andal dan direkomendasikan untuk penilaian rasa nyeri kanker serta guna pemantauan perawatan nyeri pada penderita kanker (Leppert W \& Majkowicz M, 2010). Namun dalam penerapannya di Indonesia membutuhkan pembuktian yang terstruktur, sebelum diterapkan kepada pasien kanker yang ada di layanan kesehatan kita. Maka berdasarkan paparan di atas, Penulis tertarik melakukan penelitian tentang penerapan
Brief Pain Inventory Assessment Tool untuk mengkaji nyeri pada pasien kanker,yang akan dilakukan di Lantai 8 Unit Kemoterapi Rawat Inap Zona B, Gedung A RSCM Jakarta.

\section{METODE PENELITIAN}

BPI Short Foms yang diadopsi milik Charles S. Cleeland, $\mathrm{PhD}$ dari Pain Research Group diterjemahkan ke dalam Bahasa Indonesia oleh Mahasiswa Magister dan Dosen pengajar yang menguasai Bahasa Inggris dimana berasal dari salah satu perguruan tinggi di Indonesia. Kemudian juga didiskusikan bersama Perawat Klinik berpengalaman di rumah sakit yang berbicara bahasa Inggris sehingga jadilah terjemahan BPI dari Bahasa Inggris ke Bahasa Indonesia. Setelah itu BPI versi Bahasa Indonesia diperkenalkan kepada dokter dan perawat dengan maksud meninjau terjemahan, kemudian memberikan BPI Indonesia kepada 15 orang dengan berbagai variasi karakteristik sosiodemografi dan diagnosa medis kankerserta bertanya kepada mereka apakahmereka menemukan pertanyaan membingungkan atau sulit untuk dijawab. Selanjutnya setelah penyesuaian BPI Indonesia kembali diterjemahkan ke dalam Bahasa Inggris oleh penutur Bahasa Inggris yang belum melihat BPI asli untuk membuat 
terjemahan balik ke dalam Bahasa Inggris.Hasil terjemahan kemudian dibandingkan dengan BPI dalam versi asli, kemudian oleh penutur Bahasa Inggris akan diberikan penilaian ahli apakah kedua kuisioner tersebut sudah cukup memuaskan dan sesuai.

Penelitian yang dilakukan selama 8 minggu dengan jumlah peserta yang terlibat dalam penelitian ini berjumlah 20 orang pasien kanker dengan keluhan utama nyeri kronis. Penelitian dilakukan di lantai 8 zona $A$ dan $B$, lantai 4 zona $A$ dan B sesuai dengan kriteria Peserta yang memenuhi persyaratan. Pasien yang memenuhi syarat yaitu memiliki diagnosis patologis kanker, memiliki riwayat pengalaman nyeri, jenis nyeri kronis, pasien paliatif/ kanker/tumor, dapat membaca dan menulis, dapat berkomunikasi verbal dengan jelas, hanya nyeri kronis terkait kanker dan tidak ada kondisi nyeri lainnya, tidak menjalani operasi dalam 30 hari terakhir, belum menerima terapi radiasi atau kemoterapi 30 hari terakhir, tidak memiliki infeksi atau penyulit, berusia 18 tahun atau lebih dan pasien setuju untuk membuat persetujuan tertulis

Penelitian ini merupakan analitik deskriptif degan menggunakan pendekatan cross sectional, dimana respondel atau sampel diambil secara konsekutif yaitu selama 2 bulan (oktobernovember 2017) dengan kriteria yaitu.Kemudian data dilakukan analisis menggunakan SPPS versi 17 dengan uji cronbach's alphauntuk nilai keparahan nyeri, gangguan nyeri sebesar dan untuk melihat keandalan kuisioner BPI sendiri yang dipergunakan untuk mengkaji nyeri kronis pada pasien kanker. Dalam penelitian ini akan dibuktikan apakah BPI handal dan sesuai digunakan di Indonesia, digunakan untuk menilai nyeri yang dirasakan pasien kanker yang dirawat di RSCM Jakarta. Selain itu akan dilihat nilai sesnsitivitas dan spesifitas dari kuisioner atau instrument BPI yang akan dilihat juga berdasarkan dengan skala ECOG.

\section{HASIL}

Sebagian besar Pasien dan Perawat mengisi kuesioner selama wawancara memerlukan waktu untuk menyelesaikan isian dengan rata-rata 3-5 menit.Pasien biasanya memerlukan pendampingan untuk butir pertanyaan dan bisa di isi sesuai tanggapan dari Pasien.Pasien terlihat mampu medeskripsikan keparahan nyeri, efektifitas obat dan gangguan dari nyeri yang dialaminya. Dalam penelitian, digambarkan sebaran 
responden yaitu berdasarkan jenis kelamin, usia dan tingkat pendidikan. Adapun demografi dan sebaran responden yang terlibat adalah sebagai berikut :

Tabel 1. Demografi dan Distribusi Responden berdasarkan Jenis Kelamin

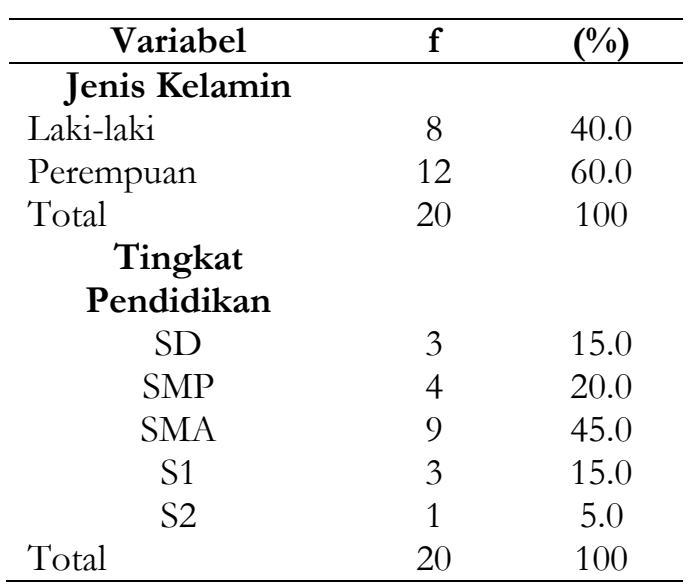

Berdasarkan Tabel 1 dari total 20 pasien kanker menunjukan sebagian besar responden adalah berjenis kelamin perempuan, yaitu sebanyak 12 orang $(60 \%)$, berusia dewasa sebanyak 19 orang (95\%) dengan rentang usia 32 tahun sampai dengan 56 tahun, dan tingkat pendidikan dari keseluruhan responden yang terlibat adalah yang terbanyak adalah lulusan sekolah menengah atas (SMA) sebanyak 9 orang (45\%). Sebaliknya data menunjukan laki-laki lebih sedikit yaitu sebanyak 8 orang $(40 \%)$, responden dengan usia lanjut 1 orang dan 1 (5\%) orang dengan pendidikan magister atau strata $2(5 \%)$.

Tabel 2. Hasil Uji Analisis Kehandalan Briefpain Inventory Tool.

\begin{tabular}{ccc}
\hline Instrumen & Cronbach's Alpha & r tabel \\
\hline VAS & 0.718 & 0,444 \\
BPI & 0.723 & 0,444 \\
\hline
\end{tabular}

Keterangan : $r$ table $\mathrm{N}$ of item $20=0,444$

Berdasarkan Tabel 2 menunjukan nilai $\mathrm{p}$ value masing-masing intrumen berada pada nilai $>0,444$. Sehingga dapat disimpulkan Brief PainInventory (BPI) memiliki kehandalan yang baik untuk mengukur dan menilai nyeri pada pasien kanker, ditunjukan dengan masingmasing nilai $p$ valuenya adalah 0,718 untukVAS dan 0,723 untuk BPI.
Dalam penelitian ini juga dinilai sensitivitas, dan spesifitas dengan Cutt Off BPI 55.77 sehingga didapatkan nilai sensitivitas $95.7 \%$ dan sensitivitas $100 \%$. Nilai Prediksi Positif (PPV) diketahui sebesar 100\% dan Niilai Prediksi Negatif yaitu $65.67 \%$ dengan rasio kemungkinan negative adalah 0.05 . 
Tabel 3. Hasil uji analisis korelasi BPI terhadap ECOG.

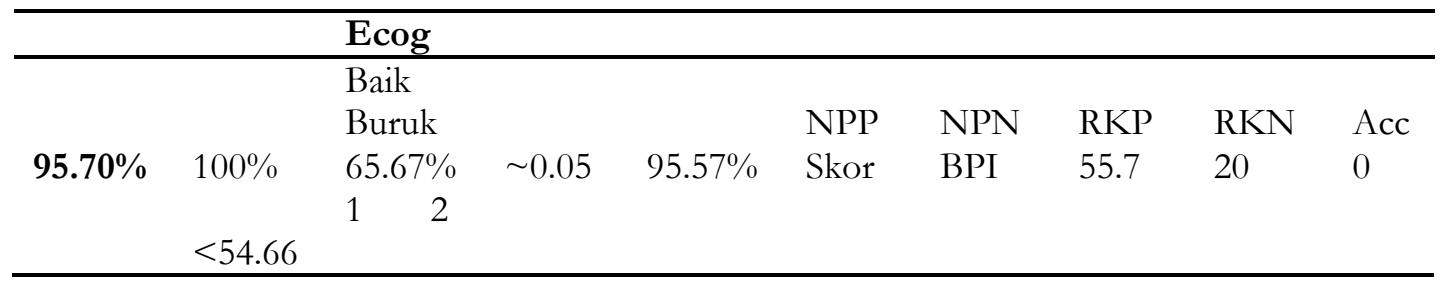

\section{PEMBAHASAN}

Assessment didefinisikan sebagai proses dokumentasi, biasanya dalam hal yang terukur, pengetahuan, keterampilan, sikap dan kepercayaandalam berbagai disiplin ilmu (Stewart J, 2014). Bedasarkan hasil uji cronbach's alpha memperlihatkan kehandalan instrument BPI dalam assessment atau mengkaji keluhan nyeri pada responden yaitu dilihat dari nilai $\alpha$ lebih dari standar yang digunakan (sufficient reliability) sebesar 0.719 . Hasil analisis kehandalan BPI berdasarkan nilai $\alpha$ adalah sebesar 0.723 dan VAS sebesar 0.718. Hasil tersebut memperlihatkan BPI akurasi dan konsistensi BPI dalam mengkaji nyeri pada pasien kanker khususnya nyeri kronis. Selain data analisis tersebut dapat diketahui juga adanya korelasi yang baik antara kemampuan BPI terhadap skor kualitas hidup yang dapat dilihat dari hasil uji spearmandilihat dari nilai ECOG $(\mathrm{r}=-0,75$, $\mathrm{p}=0,0001)$. Hasil yang didapatkan memperlihatkan sensitifitas sebesar 95.7\%, spesifisitas 100\%, PPV 100\%, NPV 65.67\%, LR(-) 0.05, dengan akurasi diagnostik 95.73\%. Dari semua hasil analisis tersebut dapat diketahui bahwa BPI SF memiliki korelasi yang baik dengan skala ECOG dan memiliki diagnostik yang sangat baik dalam memprediksi nyeri kronis.

Hasil penelitian ini diharapkan dapat meningkatkan pemantauan nyeri yang tepat pada pasien kanker dan meningkatkan kenyamanan pasien kanker dengan keluhan nyeri. Dengan metode penilaian yang komprehensif dan spesifik diharapkan memperbaiki pengelolaan nyeri lebih optimal (Erol et al, 2018). Berdasarkan penelitian ini BPI lebih sensitive dan spesifik terhadap nyeri kanker yang merupakan nyeri kronis dibandingkan pada saat menggunakan metode VAS dimana metode ini paling sering dan umum digunakan layanan kesehatan di Indonesia karena dirasakan mudah dalam aplikasinya.Sedangkan BPI adalah salah satu instrumen yang paling banyak digunakan di beberapa dunia saat ini dalam menilai nyeri kanker. 
BPI pertama kali dikembangkan di Inggris dan telah banyak digunakan di Amerika Serikat. Skala ini telah diterjemahkan ke dalam berbagai bahasa seperti Rusia, Cina, Italia, Jerman, bahasa Yunani, bahasa Spanyol, dan bahasa Jepang, BPI itu sendiri merupakan bentuk penilaian dalam skala pendek dan mudah dimengertiPerron $\mathrm{V}$ and Ronald $\mathrm{S}$ (2001). Hasil penelitian didukung beberapa hasil penelitian dimana menyampaiakan BPI merupakan suatu alat yang sesuai digunakan dalam mengkaji nyeri pasien kanker(Kees T. C. Besse et al, 2016).Seperti yang telah dibuktikan dibeberapa Negara maju dan direkomendasikan untuk penilaian rasa nyeri kanker serta guna pemantauan perawatan nyeri pada penderita kanker, BPI juga dapat diaplikasikan di Indonesia dan sesuai dengan kondisi pasien, sehingga dapat meningkatan pemantauan nyeri yang lebih komprehensif, lengkap dan mendalam. Dibandingkan dengan VAS yang merupakan instrument pengukuran intensitas nyeri yang telah digunakan secara luas dan paling umum di Indonesia termasuk masih digunakan sampai dengan saat ini di klinis RSCM.

Dari hasil penelitian diketahui bahwa data penelitiannya menunjukkan BPI merupakan pengkajian cukup singkat walaupun tidak sesederhana VAS, BPI sangat berguna dan valid untuk menilai rasa nyeri kronis serta berdampak positif terhadap kehidupan pasien. Diketahui bahwa pertanyaan BPI mencakup banyak aspek dalam pengkajian nyeri, sehingga melibatkan banyak faktor yang berpeluang mempengaruhi nyeri secara objektif dalam membantu pengelolaan nyeri oleh tim kesehatan dan memiliki dampaok positif karena mampu menilai kemampuan pasien beraktifitas. BPI memiliki kelebihan lain yaitu beberapa pertanyaan bahkan merupakan bentuk kolaborasi melalui observasi efek dari terapi medis yang telah diberikan sehingga dapatmembantu mengevalusi efikasi dari obat atau tindakan yang diberikan (Young Ho et al, 2004).

Karena sakit akibat kanker bisa sangat bervariasi selama sepanjang hari, sehingga dalam instrument BPI pasien diminta menggambarkan rasa nyeri mereka pada intensitas saat ini (rasa sakit sekarang), dan juga yang terburuk/ terparah, nyeri paling sedikit/ ringan, dan rata-rata nyeri selama minggu sebelumnya atau selama 24 jam terakhir. Melalui BPI pasien dapat menyampaikan rasa nyeri mereka yang telah mengganggu aktivitas umum seharihari, yaitu mood, berjalan, kerja, tidur, hubungan dengan orang lain, menikmati 
hidup, menggunakan nilai numerik yang dengan skala 0-10 (0 = 'tidak ada interferensi' dan $10=$ 'mengganggu sepenuhnya').

Berdasarkan hasil penelitian diketahui BPI membagi aspek penilaian melalui pertanyaannya menjadi 3 dimensi sebagai suatu spesifisitas sekaligus menjadi kelebihan dari BPI. Dari 15 pont pertanyan yang terdapat dalam BPI, poin 1-6 merupakan pertanyaan yang menilai dimensi dari intensitas nyeri pasien. poin pertanyaan tersebut menilai keparahan nyeri mulai dari skala terendah, tertinggi, kemudian merata-ratakan, bahkan menilai skala nyeri yang paling sering muncul dalam kurun waktu 24 jam terakhir. Tentunya hal tersebut sangat membantu dan memberikan data yang lebih variatif dibandingkan VAS.

BPI mengkaji respon intensitas nyeri secara berkelanjutan yaitu menanyakan dalam kurun 24 jam terakhir, artinya walaupun pada saat itu mungkin pasien tidak merasakan atau mengeluhkan nyeri, pengkajian menggunakan BPI dapat membantu penulis mengetahui riwayat kejadian nyeri dalam 24 jam. Dengan menanyakan rentang waktu 24 jam pengkajian nyeri akan lebih luas dan memmungkinkan data yang lebih akurat terkait intensitas nyeri yang sebenarnya dirasakan pasien. Selain itu rentang nyeri tertinggi pasien juga dapat terlihat di pengkajian BPI, sehingga walaupun mungkin pada saat pengkajian nyeri yang sedang dirasakan dikategorikan ringan atau sedang, data intensitas nyeri tertinggi dapat menjadi indicator resiko teerulangnya keluhan nyeri sesuai skor intensitas nyeri tertinggi yang pernah dialami pasien dalam 24 jam terakhir.

Melalui data terkaitintensitas nyeri, perawat tidak hanya mengetahui skala nyeri saatpengkajian, namun juga secara implisit dapat melihat gambaran karakteristik nyeri pasien secara lebih lengkap, perawat dapat melihat pola aktivitas nyeri pasien dalam kurun waktu 24 jam terakhir. Kemudian pada poin pertanyaan nomor 7-8 dalam pengkajian menggunakan BPI merupakan dimensi pertanyaan untuk mengetahui apa saja terapi dan ontervensi yang diterima serta diketahui oleh pasien, kemudian efek terapeutik medis dan intervensi yang telah diberikan. Melalui poin pertanyaan ini pasien menjelaskan kondisi fisiologis dan psikologis pasien terhadap nyeri setelah diberikan terapi medis. Terlihat dalam pengkajian perawat dapat mengetahui dan melakukan evaluai berkala dari efek terapi yang diberikan Burton et al (2014). 
Sehingga perawat juga dapat melakukan kolaborasi serta komunikasi 2 arah dengan pihak medis untuk membicarakan efek terapi yang dirasakan pasien terhadap nyeri yang dialami.

Sedangkan pada poin pertanyaan nomor 9 yang dibagi 9 item sub pertanyaan, merupakan dimensi pertanyaan terkait efek dari nyeri yang dialami pasien dan bertujuan untuk mengetahui sejauh mana nyeri yang dialami atau dirasakan sudah mengganggu individu pasien. dari sub pertayaan ini perawat dapat mengetahui sejauh mana nyeri telah mengganggu aktivitas umum pasien seperti aktivitas makan dan minum, menonton tv, membaca Koran, tidur atau aktivitas sehari-hari yang biasa dilakukan pasien pada umumnya. Selain itu pada sub item ini perawat dapat mengetahui gangguan nyeri terhadap suasana hati, kempuan berjalan, dan peerjaan pasien. bahkan BPI menyertakan aspek pengkajian untuk menilai sejauh mana nyeri mengganggu hubungan pasien dngan orang lain seperti anggota keluarga dan sesame pasien di RS. Sampai dengan BPI juga dapat menampilkan data pengkajian sejauh mana nyeri telah mengganggu pasien dalam menikmati kehidupannya dengan kondisi saat ini yaitu dengan kondisi sakit yang diderita (nyeri akibat kanker).
Beberapa beberapa hal bisa menjadi kekurangan dari BPI yaitu antara lain BPI yang terdiri dari 15 total item pertanyaan dapat dirasakan lebih rumit oleh beberapa perawat diruangan dibandingkan dengan pengkajian yang biasa dilakukan yaitu menggunakan VAS. Selain itu perawat juga menyampaikan durasi pengisian akan memakan waktu lebih banyak dan memungkinkan akan menyita waktu dari perawat yang sedang bertugas. Selai beberapa hal tersebut Penulis juga melihat bahwa kemungkinan tingginya subjektivitas jawaban dari pasien bisa saja sangat tinggi. Karena dipengaruhi oleh individu masing-masing dalam merespon nyeri, kondisi penyakit pasien dan situasi saat pengkajian. Berdasarkan data yang dikumpulkan rata-rata responden berjenis kelaminperempuan yaitu sebanyak 12 orang dari 20 orang keseluruhan responden yang terlibat.

Hal tersebut mengakibatkan menurut peneliti adanya overestimate dari respon pasien terhadap masing-masing pertanyaan BPI yang diberikan pada pasien. Terkadang ada beberapa data yang menunjukan nilai aspek yang bertolak belakang atau tidak saling mendukung yang dikemukakan oleh pasien. contohnya pasien mengatakan pada pertanyaan sebelumnya bahwa rata- 
rata nyeri yang dirasakan pada skala sedang (4-6), namun pada pertanyaan berikutnya pasien mnyebitkan tidak adanya gangguan tidur. Hal tersebut dapat diambil kesimpulan sementara bahwa pasien sangat subjektif dalam menyampaikan nyerinya,namun hal tersebut juga perlu dikaji dan diperhatikan lebih mendalam untuk mngetahui kebenarannya.

\section{KESIMPULAN}

Pengkajian nyeri menggunakan Brief Pain Inventory (BPI) versi bahasa Indonesiadirasakan lebih efektif dan sesuai untuk mengkaji nyeri kronis pada pasien kanker di RSCM Jakarta. Faktor paling penting adalah karena cakupan penilaian yang lebih luas dan holistic.BPI memiliki penilaian yang lebih multidimensial serta aritmatika rata-rata nyeri, gangguan akibat nyeri yang dirasakan,serta dapat digunakan sebagai gambaran kondisi biologis, psikologis, sosial, dan kultulral pasien kanker yang mengalami nyeri kronis. BPI dapat digunakan menjadi salah satu instrument untuk memantau keluhan nyeri dan sebagai salah satu standar pemantauan nyeri kronis pada pasien kanker.

\section{REFERENSI}

Alice WY (2012). A cross sectional study of use of different pain assessment tools in Chinese cancer patients. Department of Clinical Oncology, Tuen Mun Hospital, Hong Kong, China. Nova Science Publishers, Inc. J Pain Manage 2012;5(1):83-91.

Betty R \& Ferrell (2006).Assessing Cancer Pain in the Adult Patient.Oncology Vol. 20. 2006.

Burton et al (2014). Cancer pain assessment.Current Opinion in Supportive and Palliative Care: June 2014 Volume 8 - Issue 2 - p 112-116

Caraceni A \& Shkodra M (2019).Cancer Pain Assessment and Classification.Cancers 2019, 11, 510; doi:10.3390/cancers 11040510.

Cleeland CS, Gonin cR, Hatfield AK, Edmonson JH, Blum RH, Stewart JA et al (1994) Pain and its treatment in outpatients with metastatic cancer. $N$ Engl J Med 330(9):592-596.

Cluxton C (2019). The Challenge of Cancer Pain Assessment.Ulster Med J. 2019 Jan; 88(1): 43-46.

Emily A, Knobf $\mathrm{T}$ and Brant J (2010).Understanding the cancer pain experience in American Indians of the Northern Plains. PsychoOnology 20: 404-410 (2011).

Erol et al (2018). Pain experiences of patients with advanced cancer: $A$ qualitative descriptive study.Eur J Oncol Nurs. 2018 Apr;33:28-34.

Ho V. Dzung M (2010). Cancer Pain: Assessment, Diagnosis, and Management. Anesthesiology 12 2010, Vol.113, 1482.

Hølen JC, Hjermstad MJ, Loge JH, Fayers PM, Caraceni A, De Conno $\mathrm{F}$, et al.Pain assessment tools: Is the content appropriate for use in palliative care? I Pain Symptom Manage 2006;32:567-80.

Instituto Nacional de Cancer Brasil (2001) Cuidados paliativos oncológicos: 
controle da dor. Rio de Janeiro: INCAMS.

Karine A et al (2010), Validation of brief pain inventory to Brazilian patients with pain, Support Care Cancer (2011) 19:505-511.

Kees T. C. Besse et al (2016). Pain Assessment with Short Message Service and Interactive Voice Response in Outpatients with Cancer and Pain: A Feasibility Study. World Institute of Pain, Pain Practice, Volume 16, Issue 3, 2016 320-3.

Leppert W \& Majkowicz M (2010). Polish Brief Pain Inventory for Pain Assessment and Monitoring of Pain Treatment in Patients with Cancer. Journal Of Palliative Medicine. Vas. Sofias 76, 11528 Athens (Greece) Volume 13, Number 6, 2010.

Matthie N \& McMillan S (2014).Pain: a descriptive study in patients with cancer. Clin J Oncol Nurs. 2014 Apr;18(2):205-10.

Mystakidou K et al (2001). Greek Brief Pain Inventory: Validation and Utility in Cancer Pain. Pain Relief and Palliative Care Unit Areteion Hospital, University of Athens.

Ovayolu O, Ovayolu N \& Aytac S (2014).Pain in cancer patients: pain assessment by patients and family caregivers and problems experienced by caregivers. Springer-Verlag Berlin Heidelberg. 2014.

Perron V and Ronald S (2001).Assessment and Management of Pain in Palliative Care Patients.Cancer Control, January/February 2001, Vol. 8, No.1.
Rahi C E et al (2017). Pain Assessment Practices in Patients with Cancer Admitted to the Oncology Floor. J Hematol Oncol Pharm. 2017;7(3):109-113.

Saggini R et al (2015). Cancer Pain : The Role of an Integrated, Comprehensive Rebabilitation Program in Its Management. Science Core Collection (BKCI). 2015.

Senthil P Kumar (2011). Utilization of Brief Pain Inventory as an Assessment Tool for Pain in Patients with Cancer: A Focused Review. Indian Journal of Palliative Care / May-Aug 2011 / Vol-17 / Issue-2.

Situ D, Wang J, \&Zhu ZH (2012). Assessment and treatment of cancer pain: From Western to Eastern. Ann Palliat Med 2012;1(1):32-44.

Stewart J (2014). The Challenges of Cancer Pain Assessment.Ulster Med J. 2014 Jan; 83(1): 44-46.

Suresh K \& Hill S (2002). Assessment and Management of Cancer Pain.2002. 3601_e23_p493-535.

The British Pain Society's (2010).Cancer Pain Management. A perspective from the British Pain Society, supported by the Association for Palliative Medicine and the Royal College of General Practitioner. The British Pain Society.2010;p 25-31.

World Health Organization - Cancer Country Profiles, 2014.http:/ / www.who.int/en.

Young Ho et al (2004). Development of a Cancer Pain Assessment Tool in Korea: A $V$ alidation Study of a Korean Version of the Brief Pain Inventory. Oncology 2004;66:439-444. 